\title{
Inter-Spousal Communication on Family Planning and Its Effect on Contraceptive Use and Method Choice in Bangladesh
}

\author{
Md. Shahidul Islam ${ }^{1}$, Muhammad Shafiul Alam² \& Md. Mahedi Hasan ${ }^{3}$ \\ ${ }^{1}$ Department of Sociology, Shahjalal University of Science and Technology, Sylhet, Bangladesh \\ ${ }^{2}$ Department of Public Administration, Shahjalal University of Science and Technology, Sylhet, Bangladesh \\ ${ }^{3}$ Department of Statistics, Shahjalal University of Science and Technology, Sylhet, Bangladesh \\ Correspondence: Md. Shahidul Islam, Department of Sociology, Shahjalal University of Science and Technology \\ (SUST), Sylhet, Bangladesh. Tel: 88-017-2291-8936. E-mail: shahidulsoc@gmail.com
}

Received: October 1, 2013 Accepted: November 24, 2013 Online Published: December 29, 2013

doi:10.5539/ass.v10n2p189 URL: http://dx.doi.org/10.5539/ass.v10n2p189

\begin{abstract}
Inter-spousal communication is largely influenced to couples on contraceptive use and the decision of appropriate method choice. This paper examined the effects of inter-spousal communication on contraceptive use and method choice in Bangladesh. A total 451 married men aged 15-49 were interviewed from Narsingdi municipality, Bangladesh. Bivariate analysis as chi square test was applied to examine the relationship between spousal communication as well as other socio-demographic variables on contraceptive use. Binary logistic regression was applied to examine the effect of spousal communication on contraceptive use and multinomial logistic regression was applied to examine the effect of spousal communication on method choice. Binary logistic regression showed that inter spousal communication on family planning has strong positive effect on current contraceptive use and multinomial logistic regression showed that inter spousal communication has positive effect on choosing modern and tradition method than none using any method. However, age of husband, age of women, number of living children, media exposure, knowledge on contraception, husband and women occupation, and couple's income were also associated with contraceptive use and method choice in Bangladesh.
\end{abstract}

Keywords: spousal communication, contraceptive, logistic regression, family planning, Bangladesh

\section{Introduction}

Bangladesh is a male dominant country. Due to cultural factors male are always ignoring to share equal responsibility about family planning. Because of Bangladesh is a patriarchal society, husband has most authority over their wives about next birth, the number of children and when to stop childbearing and women do not have any control of their reproductive health related issues (Kamal \& Islam, 2012). So, most of the family planning programmes are unsuccessful because of low participation of male in family planning and reproductive health related issues. Spousal communication is an important basis for decision making about reproductive health, sexual needs and desired family size and increased contraceptive use and modern method choice of family planning. The communication of couples is necessary for successful planning and decision-making about fertility size and use of contraceptive. The processes of couples' communication have major consequences for number of children, timing of birth and contraceptive adoption. In Bangladesh, most of the females are took part in the family planning programme. After involving this programme, women find sufficient knowledge about benefit of small family size, about the right contraceptive method. Through inter-spousal communication, women are influenced to male about to take small family size, about to suitable contraceptive use and other reproductive issues. Through spousal communication husband and wife make mutual consensus about the family size and the choice of appropriate methods (Shrestha, 2009). Spousal communication can play a vital role not only partners in their reproductive decision making but also seeking appropriate treatment of their reproductive health (Karvande, 2009). Inter-spousal communication between husband and wife largely influence on couples reproductive health and fertility intension. Interposal communications help them to make better reproduction decision (Islam et al., 2010). Through inter-spousal communication, couples have better understanding about the advantages and disadvantages of contraceptive method (Islam, 2010). On the other hand, accidental pregnancy outcomes, sexually transmitted diseases (STD) transmission and unsafe abortions were occurred due to lack of inter-spousal communication (Islam et al., 2010). Women's inferior position is also reason of couples lack spousal 
communication.

There are many researches in Bangladesh focused to identify the socioeconomic, cultural and demographic factors that influence to use of contraceptive and fertility intention. But the role of husband wife communication on family planning has been ignored by the family planning programs (Kamal \& Islam, 2012). There were few studies in Bangladesh focus on about the inter-spousal communication on family planning. So, this study examines the effects of husband and wife communication on current contraceptive use and method choice of couples in Bangladesh.

\subsection{Review of Literature}

Inter-spousal communication is most important in Bangladesh for contraceptive use and appropriate method choice. Kamal and Islam (2012) examined that inter-spousal communication influenced on couple's contraceptive use in Bangladesh. They found that husband-wife discussion largely influenced to couples contraceptive adoption. Among the socioeconomic factors, son preference, residence, region and recently field work visitations were also influence to couples contraceptive use. Although inter-spousal communication influences to couples, the rate of spousal communication is very low in Bangladesh. Islam et al. (2010) found that inter-spousal communication was very low in Bangladesh. Most of the couples did not use contraceptive by taking joint decision. Higher socio-economic position leads to couples on inter-spousal communication. They found that inter spousal communication was high among the couples who have high education, more current living children, approved of family planning, had media exposure. So they were more likely to use contraceptive. Rasheed et al. (2011) found that inter-spousal communication was more important in male domination country. They found in India that inter-spousal communication was positively associated with contraceptive use. Derose et al. (2004) found that contraceptive use was larger among who had discussed about family planning with each other's. So, spousal communication is more important to unmet need for contraception use in Bangladesh. Tuloro et al. (2006) considered spousal communication was an important factor to contraceptive use in Hossana Town, Southern Ethiopia. They found that couples were 17.3 times more likely to use contraceptive that have inter-spousal communication compared to that had no inter-spousal communication about family planning. By using a longitudinal data, Nahar (2005) showed that inter-spousal communication was increasing over time in Matlab, Bangladesh. She found that contraceptive prevalence rate was higher among the couples who had frequently discussed with each other's about reproductive issues. So, inter-spousal communication can be considered as a good strategy to choice appropriate method choice and about small fertility intension in Bangladesh.

\subsection{Objectives of the Study}

\subsubsection{Objective of the Study}

1) To examine the effects of inter spousal communication on current contraceptive use.

2) To examine the effects of inter spousal communication on contraceptive method choice.

3) To examine the socio-demographic factors and contraceptive use and method choice.

\section{Data and Methods}

\subsection{Research Design}

This was a cross-sectional study. Social survey method was applied to this study.

\subsection{Research Area and Location}

Narsingdi municipality was purposively selected as study field since this municipality is famous for industrial area.

\subsection{Data Collection Technique}

Data were collected from the 20-49 years male group because it is the best time for discussing about family planning about the reproductive related issues. Semi-structure questions were included in the questionnaire and data were collected by interview method.

\subsection{Sampling and Sample Size}

A two stage cluster sampling procedure was applied to pick up appropriate sample size. Three municipal wards named (ward no 3, ward no 8 and ward no 2) are randomly selected from this area. Among those three wards, 451 samples selected through appropriate cluster sampling techniques. 


\subsection{Statistical Techniques}

The SPSS version 20 has been used to analyze the data. To explore the background characteristics of the respondents some univariate techniques such as frequency distribution have used. Besides this some bivariate and multivariate techniques also applied to determine the effects of spousal communication on contraceptive use and methods choice. Test for association between independent and dependent variables also examined by chi square statistic. Variables those were found significant in bivariate analysis used for establishing the cause and effect relationship. Logistic regression analysis have used since the outcome variable has categorical responses. Husband occupation was found insignificant for contraceptive use. So, this variable excluded from logistic regression. The first model (model 1) binary logistic regression was applied to determine only spousal communication effects on contraceptive without including other socio-demographic factors and the second model (model 2) included other socio economic factors those were found significant in bivaraite analysis. To determine the effects of spousal communication on method choice, multinomial logistic regression was applied because the trichotomous nature of the outcome variable. The third model (model-3) was applied to determine only spousal communication's effects on method choice without including other socio demographic factors and (model-4) fourth model included other socio-demographic factors.

\subsection{Independent Variable}

Inter spousal communication: Inter spousal communication refers to men's reports about whether they discuss the most recent discussion on family planning with their wives within the last six months. The measurement of inter-spousal communication was derived from six questions. Inter spousal communication was measured by summing scores (yes $=1, n_{0}=0$ ) for each question and dichotomized scores (unfavorable $=0-3$, favorable $=4-6$ ). High scores represented higher favorable spousal communication and lowest score represented the unfavorable spousal communication to contraceptive use.

\subsection{Reliability}

To measure the internal consistency reliability of the inter-spousal communication, Cronbach's Alpha was applied. The internal consistency reliability was found 0.86 which was good.

\subsection{Other Socio Demographic Variables}

Age of husband, age of women, husband education, women education, husband occupation, women occupation, couple's income, number of living children, knowledge on contraceptive and media exposure.

\subsection{Dependent Variable}

Contraceptive use: Contraceptive use refers to the use of any modern or traditional contraceptive method. The modern methods includes such as pill, condom, IUD, injectable, Norplant, Diaphragm, jelly, foam, male and female sterilization and traditional methods includes such as withdrawal, safe periodic abstinence by currently married couples during the time of interview. Currently contraceptive use has been measured by asking question on contraceptive use or not use, either "yes" or "no" answers at the time of interview. Then the method choice of contraceptive includes trichotomous variable such as not using any method, using any traditional method and using any modern method.

\section{Result}

Table 1. Background profile of the respondents

\begin{tabular}{lll}
\hline variables & Frequency & Percent \\
\hline Age of husband & & 31.7 \\
$20-30$ & 143 & 37.3 \\
$30-40$ & 168 & 31.0 \\
$40-49$ & 140 & 100.0 \\
Total & 451 & \\
Age of women & & 39.9 \\
Less than 24 & 180 & 38.4 \\
$25-34$ & 173 & 21.7 \\
$35+$ & 98 & \\
\hline
\end{tabular}




\begin{tabular}{|c|c|c|}
\hline variables & Frequency & Percent \\
\hline Total & 451 & 100.0 \\
\hline \multicolumn{3}{|l|}{ Education of husband } \\
\hline No education. & 98 & 21.7 \\
\hline Primary & 79 & 17.5 \\
\hline Secondary & 84 & 18.6 \\
\hline Higher secondary & 99 & 22.0 \\
\hline Bachelor and above & 91 & 20.2 \\
\hline Total & 451 & 100.0 \\
\hline \multicolumn{3}{|l|}{ Women education } \\
\hline No education & 123 & 27.3 \\
\hline Primary & 156 & 34.6 \\
\hline Secondary & 99 & 22.0 \\
\hline Higher secondary and above & 73 & 16.2 \\
\hline Total & 451 & 100.0 \\
\hline \multicolumn{3}{|l|}{ Husband occupation } \\
\hline Unskilled workers & 227 & 50.3 \\
\hline Skilled & 174 & 38.6 \\
\hline Professional & 50 & 11.1 \\
\hline Total & 451 & 100.0 \\
\hline \multicolumn{3}{|l|}{ Women occupation } \\
\hline Not working & 321 & 71.2 \\
\hline Semi-skilled and unskilled labor & 72 & 16.0 \\
\hline Business and services & 58 & 12.9 \\
\hline Total & 451 & 100.0 \\
\hline \multicolumn{3}{|l|}{ Couple's income(Taka) } \\
\hline Less than 8000 & 131 & 29.0 \\
\hline $8000-16000$ & 192 & 42.6 \\
\hline $16000+$ & 128 & 28.4 \\
\hline Total & 451 & 100.0 \\
\hline \multicolumn{3}{|l|}{ Current living children } \\
\hline 0 & 56 & 12.4 \\
\hline 1 & 75 & 16.6 \\
\hline 2 & 147 & 32.6 \\
\hline $3+$ & 173 & 38.4 \\
\hline Total & 451 & 100.0 \\
\hline \multicolumn{3}{|l|}{ Number of methods known } \\
\hline Less than 5 & 165 & 36.6 \\
\hline Above 5 & 286 & 63.4 \\
\hline Total & 451 & 100.0 \\
\hline \multicolumn{3}{|l|}{ Media exposure } \\
\hline No & 121 & 26.8 \\
\hline Yes & 330 & 73.2 \\
\hline Total & 451 & 100.0 \\
\hline Spousal Communication & & \\
\hline
\end{tabular}




\begin{tabular}{lll}
\hline variables & Frequency & Percent \\
\hline Unfavorable & 181 & 40.1 \\
Favorable & 270 & 59.9 \\
Total & 451 & 100.0 \\
Using of Contraception & & \\
No & 178 & 39.5 \\
Yes & 273 & 60.5 \\
Total & 451 & 100.0 \\
Using methods & & \\
Not using any method & 178 & 39.5 \\
Any tradition method & 29 & 6.4 \\
Modern method & 244 & 53.1 \\
Total & 451 & 100.0 \\
\hline
\end{tabular}

In regarding to occupation, $71.2 \%$ wives were not working and all the men were working any kinds of occupation. Husbands were unskilled $50.3 \%$ workers and women were $16 \%$ working as semi-skilled and unskilled workers. A few numbers of husband $11.1 \%$ and wife $12.9 \%$ were engaged professional works. About $38.4 \%$ men had three or above children and $32.6 \%$ had two children and $16.6 \%$ had one child. Only $12.2 \%$ men had no children. Majority of the couples $42.6 \%$ income were between 8000 to 16000 tk. Concerning knowledge on contraceptive $63.4 \%$ of man knowledge level was high and $36.6 \%$ of men knowledge level was low. Overall, $47.6 \%$ of the married men currently used any family planning methods with their wives or partners. About $15 \%$ of them reported having used a family planning method at some time, but not currently using one, while $37.8 \%$ reported never having used contraceptives $60.5 \%$ men currently using any kinds of family planning method and $39.5 \%$ men not using any method. A majority number $53.1 \%$ were using modern method and $6.4 \%$ were using traditional method. As shows in the table, more than half $59.9 \%$ of the men had favorable communication on family planning with their wives in the last three months prior to the survey. Majority $73.4 \%$ men had at least one media exposure.

\subsection{Factors Related to Inter-Spousal Communication}

Table 2. Factors related to spousal communication

\begin{tabular}{llllll}
\hline \multirow{2}{*}{ variables } & \multicolumn{2}{l}{ Spousal communication } & & \\
& Unfavorable & Favorable & total & Chi square value & P value \\
\hline Age of husband & & & & & \\
Less than 30 & $49.7 \%$ & $50.3 \%$ & 143 & & .019 \\
$30-39$ & $35.1 \%$ & $64.9 \%$ & 168 & 7.949 & \\
$40-49$ & $36.4 \%$ & $63.6 \%$ & 140 & & \\
Total & $40.1 \%$ & $59.9 \%$ & 451 & \\
Age of women & & & & \\
less than 25 & $45.0 \%$ & $55.0 \%$ & 180 & \\
$25-34$ & $34.7 \%$ & $65.3 \%$ & 173 & 3.933 \\
$35+$ & $40.8 \%$ & $59.2 \%$ & 98 & \\
Total & $40.1 \%$ & $59.9 \%$ & 451 & \\
Education levels of husband & & & & \\
No education & $73.5 \%$ & $26.5 \%$ & 98 & \\
Primary & $36.7 \%$ & $63.3 \%$ & 79 & \\
Secondary & $29.8 \%$ & $70.2 \%$ & 84 & 62.900 \\
Higher secondary & $35.4 \%$ & $64.6 \%$ & 99 & \\
Graduated and above & $22.0 \%$ & $78.0 \%$ & 91 & \\
\hline
\end{tabular}




\begin{tabular}{|c|c|c|c|c|c|}
\hline \multirow[b]{2}{*}{ variables } & \multicolumn{5}{|c|}{ Spousal communication } \\
\hline & Unfavorable & Favorable & total & Chi square value & $P$ value \\
\hline Total & $40.1 \%$ & $59.9 \%$ & 451 & & \\
\hline \multicolumn{6}{|l|}{ Women's education } \\
\hline No & $62.6 \%$ & $37.4 \%$ & 123 & & \\
\hline Primary & $35.9 \%$ & $64.1 \%$ & 156 & & \\
\hline Secondary & $30.3 \%$ & $69.7 \%$ & 99 & 38.267 & .000 \\
\hline Higher secondary and above & $24.7 \%$ & $75.3 \%$ & 73 & & \\
\hline Total & $40.1 \%$ & $59.9 \%$ & 451 & & \\
\hline \multicolumn{6}{|l|}{ Husband's occupation } \\
\hline Unskilled workers & $52.4 \%$ & $47.6 \%$ & 227 & & \\
\hline Semi-skilled & $31.0 \%$ & $69.0 \%$ & 174 & 32.386 & .000 \\
\hline Skilled & $16.0 \%$ & $84.0 \%$ & 50 & & \\
\hline Total & $40.1 \%$ & $59.9 \%$ & 451 & & \\
\hline \multicolumn{6}{|l|}{ Women's occupation } \\
\hline Housewife & $38.9 \%$ & $61.1 \%$ & 321 & & \\
\hline Unskilled & $52.8 \%$ & $47.2 \%$ & 72 & 6.980 & .031 \\
\hline Skilled & $31.0 \%$ & $69.0 \%$ & 58 & & \\
\hline Total & $40.1 \%$ & $59.9 \%$ & 451 & & \\
\hline \multicolumn{6}{|l|}{ Couple's income(taka) } \\
\hline less than 8000 & $52.7 \%$ & $47.3 \%$ & 131 & & \\
\hline $8000-16000$ & $39.1 \%$ & $60.9 \%$ & 192 & 15.378 & .000 \\
\hline above 16000 & $28.9 \%$ & $71.1 \%$ & 128 & & \\
\hline Total & $40.1 \%$ & $59.9 \%$ & 451 & & \\
\hline \multicolumn{6}{|l|}{ Current living children } \\
\hline 0 & $46.4 \%$ & $53.6 \%$ & 56 & & \\
\hline 1 & $42.7 \%$ & $57.3 \%$ & 75 & & \\
\hline 2 & $40.1 \%$ & $59.9 \%$ & 147 & 1.834 & .608 \\
\hline $3+$ & $37.0 \%$ & $63.0 \%$ & 173 & & \\
\hline total & $40.1 \%$ & $59.9 \%$ & 451 & & \\
\hline \multicolumn{6}{|l|}{ Number of methods known } \\
\hline Less than 5 & $52.1 \%$ & $47.9 \%$ & 165 & & \\
\hline Above 5 & $33.2 \%$ & $66.8 \%$ & 286 & 15.564 & .000 \\
\hline Total & $40.1 \%$ & $59.9 \%$ & 451 & & \\
\hline \multicolumn{6}{|l|}{ Media exposure } \\
\hline No & $56.2 \%$ & $43.8 \%$ & 121 & & \\
\hline Yes & $34.2 \%$ & $65.8 \%$ & 330 & 17.764 & .000 \\
\hline Total & $40.1 \%$ & $59.9 \%$ & 451 & & \\
\hline
\end{tabular}

From this table shows that, age of husband, education of husband, husband occupation, women education, women occupation, couple's income, number of methods known and media exposure were related to couples inter-spousal communication. But the Chi -square test shows that the age of women and current living children have no significant association on husband wife inter-spousal communication about family planning.

Age of husband was associated with interposal communication about family planning in this area. Husband age groups belongs to $30-39$ years and $40-49$ years, were $64.9 \%$ and $63.6 \%$ discussed with wife about family planning compare to those have age less than 30 years. So, inter-spousal communication differences with the differences of age group of husband. Lower age groups of husband are less likely to discuss with wife about family planning.

Husband education was considered important when discussing family planning with each other. It is found that 
highest inter-spousal communication $78.0 \%$ observed on those who had the graduates and above in education and the lowest highest inter-spousal communication $26.5 \%$ observed who had no education. Therefore, the inter-spousal communication on family planning increases with the increase of level of education of husband. Respectively, women education was also associated with inter-spousal communication about family planning. Women who had higher secondary and above education, $69.7 \%$ discussed with their husband about family planning and inter-spousal communication was lower (37.4\%) among those who had no education.

Husband's occupation was significantly associated with inter-spousal communication about family planning. Husband who were unskilled workers, semi-skilled, skilled had discussed with wife about family planning $47.6 \%, 69.0 \%$ and $84.0 \%$ respectively. So, inter-spousal communication about family planning increases with the increases of level of occupational status of husband.

Couple's income was also associated with inter-spousal communication about family planning couple's that had less than 8000 taka monthly income had $47.3 \%$ discussed about husband-wife each other about family planning. Moreover, couples had highest $71.1 \%$ inter-spousal communication about family planning who had household income was above 16000 taka monthly.

Of the husband who has known less than five family planning methods, $47.9 \%$ have unfavorable interposal communication but husbands who has known above more than five family planning methods, $66.8 \%$ have favorable spousal communication.

The results show that the inter-spousal communication was higher (65.5\%) among the respondents who had media exposure while inter-spousal communication was lower (43.8\%) among those married couples who do not have media exposure.

\subsection{Factors Related to Contraceptive Use}

Table 3. Factors related to socio-demographic variable on contraceptive use

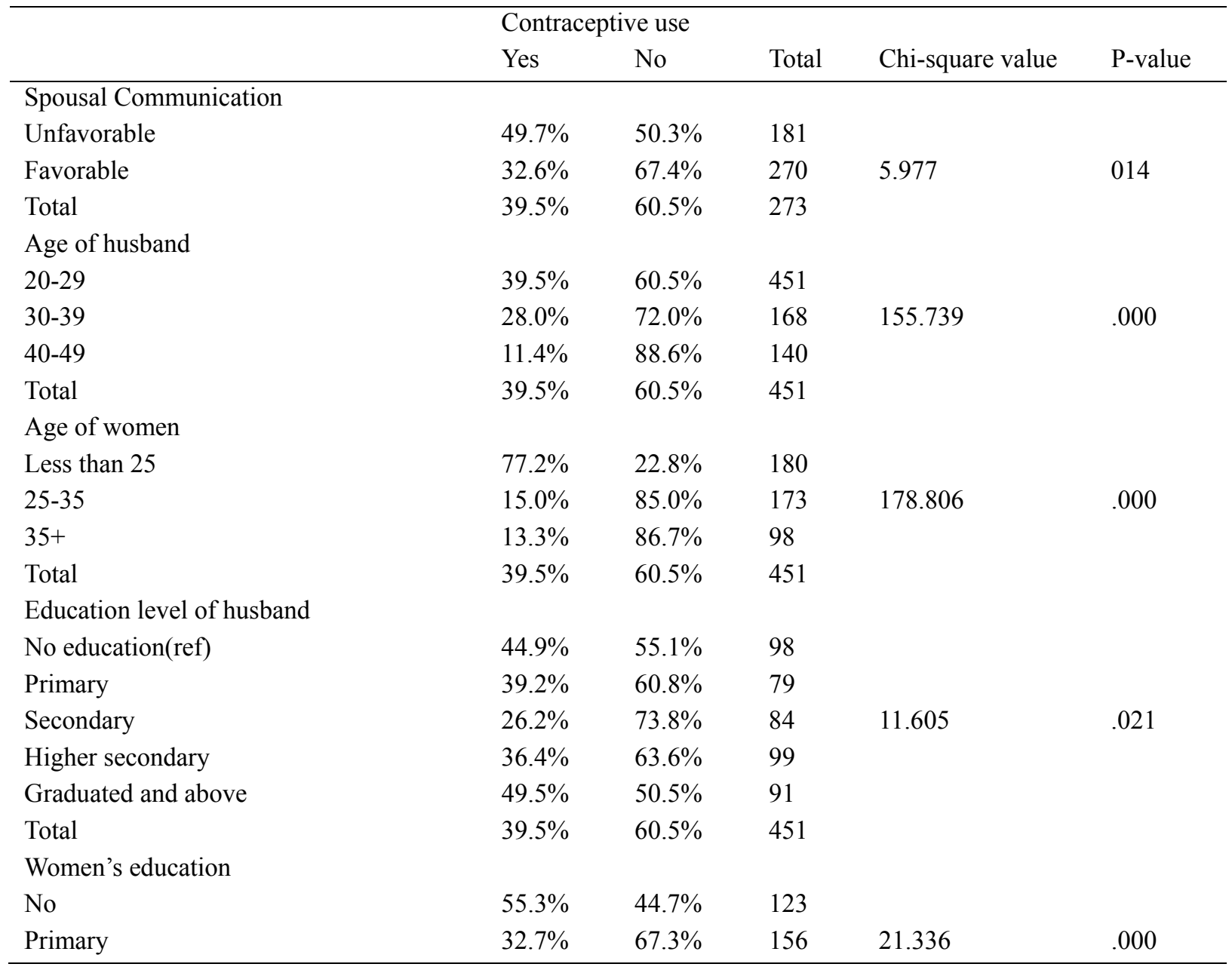




\begin{tabular}{|c|c|c|c|c|c|}
\hline & \multicolumn{3}{|c|}{ Contraceptive use } & \multirow[b]{2}{*}{ Chi-square value } & \multirow[b]{2}{*}{ P-value } \\
\hline & Yes & No & Total & & \\
\hline Secondary & $28.3 \%$ & $71.7 \%$ & 99 & & \\
\hline Higher & $42.5 \%$ & $57.5 \%$ & 73 & & \\
\hline Total & $39.5 \%$ & $60.5 \%$ & 451 & & \\
\hline \multicolumn{6}{|l|}{ Husband's occupation } \\
\hline Unskilled workers & $42.7 \%$ & $57.3 \%$ & 227 & & \\
\hline Skilled & $36.2 \%$ & $63.8 \%$ & 174 & 2.038 & 361. \\
\hline Professional & $36.0 \%$ & $64.0 \%$ & 50 & & \\
\hline Total & $39.5 \%$ & $60.5 \%$ & 451 & & \\
\hline \multicolumn{6}{|l|}{ Women's Occupation } \\
\hline Not working & $38.0 \%$ & $62.0 \%$ & 321 & & \\
\hline Semi-skilled and unskilled labor & $54.2 \%$ & $45.8 \%$ & 72 & 9.303 & .010 \\
\hline Business and Services & $29.3 \%$ & $70.7 \%$ & 58 & & \\
\hline Total & $39.5 \%$ & $60.5 \%$ & 451 & & \\
\hline \multicolumn{6}{|l|}{ Income } \\
\hline Less than 10,000 & $48.1 \%$ & $51.9 \%$ & 131 & & \\
\hline $10,000-20,000$ & $37.5 \%$ & $62.5 \%$ & 192 & 6.238 & .044 \\
\hline Above 20,000 & $33.6 \%$ & $66.4 \%$ & 128 & & \\
\hline Total & $39.5 \%$ & $60.5 \%$ & 451 & & \\
\hline \multicolumn{6}{|l|}{ Current living children } \\
\hline 0 & $82.1 \%$ & $17.9 \%$ & 56 & & \\
\hline 1 & $60.0 \%$ & $40.0 \%$ & 75 & & \\
\hline 2 & $27.2 \%$ & $72.8 \%$ & 147 & 76.122 & .000 \\
\hline $3+$ & $27.2 \%$ & $72.8 \%$ & 173 & & \\
\hline Total & $39.5 \%$ & $60.5 \%$ & 451 & & \\
\hline \multicolumn{6}{|l|}{ Number of methods known } \\
\hline Less than 5 & $49.1 \%$ & $50.9 \%$ & 165 & & \\
\hline Above 5 & $33.9 \%$ & $66.1 \%$ & 286 & 10.085 & .001 \\
\hline Total & $39.5 \%$ & $60.5 \%$ & 451 & & \\
\hline \multicolumn{6}{|l|}{ Media exposure } \\
\hline No & $48.8 \%$ & $51.2 \%$ & 121 & & \\
\hline Yes & $36.1 \%$ & $63.9 \%$ & 330 & 5.977 & 014. \\
\hline Total & $39.5 \%$ & $60.5 \%$ & 451 & & \\
\hline
\end{tabular}

The table shows that the spousal communication was highly associated with contraceptive use. The results show that the contraception use rate was higher among couples $(50.3 \%)$ who had favorable spousal communication compared to those (67.4\%) who had unfavorable spousal communication. About $19.65 \%$ men use contraceptive whose age of husband was 20-29 group, $72.0 \%$ with age of husband 30-39 and 88.6 percent with age was 40-49. It was observed that use of contraception was proportionally higher among higher aged men compared with whose had lower aged men. The proportion of contraceptive user increase as age of the men increases. Women age was also associated with contraceptive use. About $22.8 \%$ women used contraceptive whose age of women was $20-29,85.0 \%$ with age of women was $25-35$ group and $86.7 \%$ with age was $40-49$ groups. So, contraceptive use increases as the age of women increases. Contraceptive use was also associated with education of women. The contraceptive use rate was low (55.1\%) among women who were illiterate. The rates of contraceptive use were 60.8 percent, 73.8 percent and 63.6 and 50.5 percent among couples where women got primary education, secondary education higher secondary and above education respectively. Occupation of husband was also associated with contraceptive use. The result shows that use of contraception was higher among the skilled workers (57.3 percent) and among the professionals (63.8 percent). The contraceptive use was lower (64.5 percent) among unskilled workers. Women occupation is also found with the contraceptive use. In this study, the 
highest percentages of females (45.8 percent) who were currently practicing contraceptive methods are not engaged in any work outside their family. The contraceptive use rate was $70.7 \%$ among couples where wives were semiskilled and unskilled laborers and $48.3 \%$ where wives were involved with business and other services. The study reveals that contraceptive use rate is higher among couples where wives are working compared with those who are not working. Couple's income was also associated with contraceptive use. About 51.9 percent men use contraceptive whose income was less than 8000 taka, 62.5\% with income 8000-16000 taka and 66.4 percent with couple's income above 16000 taka. Contraceptive use is positively associated with number of living children. The contraceptive use rate was very low (17.9\%) among the couples who have no living children. The contraceptive use rate among couples who had two, three and four or more children were 40.0 percent, 72.8 percent and 72.8 percent respectively. The results show that the contraceptive use was higher (51.2 percent) among the respondents who have high knowledge on contraception while contraceptive use was lower (63.9percent) among those married couples who do not have adequate knowledge on contraception.

\subsection{Effects of Spousal Communication on Contraceptive Use}

Table 4. Binary logistic regression show the odds of currently using contraceptive

\begin{tabular}{|c|c|c|}
\hline Variables & $\begin{array}{l}\text { Model-1 } \\
\text { Odds ratio }\end{array}$ & $\begin{array}{l}\text { Model-2 } \\
\text { Odds ratio }\end{array}$ \\
\hline \multicolumn{3}{|l|}{ Spousal communication } \\
\hline \multicolumn{3}{|l|}{ Unfavorable(Ref) } \\
\hline Favorable & $2.045 * *$ & $2.065 * *$ \\
\hline \multicolumn{3}{|l|}{ Age of husband } \\
\hline \multicolumn{3}{|l|}{ 20-29(Ref) } \\
\hline $30-39$ & & $3.196 * *$ \\
\hline $40-49$ & & $6.811 * * *$ \\
\hline \multicolumn{3}{|l|}{ Age of women } \\
\hline \multicolumn{3}{|l|}{ Less than 25 (ref) } \\
\hline $25-35$ & & $8.557 * * *$ \\
\hline $35+$ & & $6.433 * * *$ \\
\hline \multicolumn{3}{|l|}{ Education level of husband } \\
\hline \multicolumn{3}{|l|}{ No education(ref) } \\
\hline Primary & & .811 \\
\hline Secondary & & .622 \\
\hline Higher secondary & & .286 \\
\hline Graduated and above & & $.064 * * *$ \\
\hline \multicolumn{3}{|l|}{ Women's education } \\
\hline \multicolumn{3}{|l|}{ No (Ref) } \\
\hline Primary & & $2.291 * *$ \\
\hline Secondary & & $4.334 * *$ \\
\hline Higher secondary and above & & $5.093 * *$ \\
\hline \multicolumn{3}{|l|}{ Women's occupation } \\
\hline \multicolumn{3}{|l|}{ Not working(Ref) } \\
\hline Semi-skilled and unskilled labor & & $.410 * *$ \\
\hline Business and service & & $2.502^{*}$ \\
\hline \multicolumn{3}{|l|}{ Couple's income(taka) } \\
\hline \multicolumn{3}{|l|}{ less than $10,000(\mathrm{Ref})$} \\
\hline $10,000-20,000$ & & 1.464 \\
\hline above 20,000 & & 1.808 \\
\hline \multicolumn{3}{|l|}{ Number of living children } \\
\hline 0 (Ref) & & \\
\hline
\end{tabular}




\begin{tabular}{|c|c|c|}
\hline & Model-1 & Model-2 \\
\hline Variables & Odds ratio & Odds ratio \\
\hline & & $3.017^{*}$ \\
\hline 2 & & $6.509 * *$ \\
\hline $3+$ & & $3.254 * *$ \\
\hline \multicolumn{3}{|l|}{ Number of methods known } \\
\hline \multicolumn{3}{|l|}{ Less than 5(ref) } \\
\hline Above 5 & & $1.971^{*}$ \\
\hline \multicolumn{3}{|l|}{ Media exposure } \\
\hline \multicolumn{3}{|l|}{ No (Ref) } \\
\hline Yes & & 1.086 \\
\hline Ref=reference category & & \\
\hline
\end{tabular}

Spousal communication and contraceptive use: The odds ratio implies that couples were 2.045 times more likely to use contraceptive those had favorable spousal communication compared with who had unfavorable spousal communication (without adjusting other socio-demographic variable) (model-1). The table shows that the couples who had favorable spousal communication were 2.065 times more likely to use contraceptive than who had unfavorable spousal communication (model-2).

So it is clear that spousal communication is positively associated with contraceptive use.

\subsection{Effects of Other Socio-Demographics Variables}

The odds ratio implies that couples were 1.917 times higher using contraceptive that were known above five methods compared with who have known less than five methods. The couples where husband age 30-39 years they were 3.196 times more likely to use contraceptive than those age were 20-29. Similarly, when husband hold 40-49 age, the likelihood of contraceptive use was 6.811 times higher than those had age 20-29 years. When women age hold 30-39 years they were 8.557 times more likely to use contraceptive than those age 20-29. Similarly, when women belong to hold 40-49 ages, the likelihood of contraceptive use was 6.433 times higher than those have age 20-29 years.

The odds ratio implies that couples were 6.509 times more likely to use contraceptives those who had two children compared with the reference group than who had no children. Men were 3.254 times more likely to use contraceptives those who had three and above children. Women who work business and services were 3.436 times more likely to use contraceptives compared to women who do not work any earning activities or work inside the home such as housewife and women are semi-skilled and unskilled worker. 416 times less likely to use contraceptives those who do not work. The odds ratio implies that couples were 5.093 times more likely to use contraceptive that had higher education and couples were 2.291 times more likely to use contraceptive that have primary education.

\subsection{Effects of Spousal Communication on Contraceptive Method Choice}

Table 5. Multinomial regression shows the factor associated with method choice (without other socio-economic factor) (model-3)

\begin{tabular}{llll}
\hline Modern vs. no method & Odds ratio & Traditional vs. no method & Odds ratio \\
\hline Spousal communication & & Spousal communication & \\
Unfavorable (Ref) & & Unfavorable (Ref) & \\
Favorable & $2.654^{* * *}$ & Favorable & $1.949^{* *}$ \\
\hline
\end{tabular}

Ref=reference category

Significant at ${ }^{*} p<0 \cdot 10 ;{ }^{* *} p<0 \cdot 05 ;{ }^{* * *} p<0 \cdot 01$;

Spousal communication was related to use modern contraceptive method (without including other 
socio-demographics variable. When spousal communication was favorable, couples were 2.654 times more likely to use modern contraceptive than not using any method. Similarly, couples were 1.949 times more likely to use traditional method than not using any method when had spousal communication was favorable.

Table 6. Multinomial regression show the factor associated with method choice

\begin{tabular}{|c|c|c|c|}
\hline Modern vs. no method & Odds ratio & Traditional vs. no method & Odds ratio \\
\hline Spousal communication & & Spousal communication & \\
\hline Unfavorable(Ref) & & Unfavorable(Ref) & \\
\hline Favorable & $2.703^{*}$ & Favorable & $1.907 * *$ \\
\hline Age of husband & & Age of husband & \\
\hline 20-29(Ref) & & 20-29(Ref) & \\
\hline $30-39$ & $4.352^{* *}$ & $30-39$ & 2.740 \\
\hline $40-49$ & $6.939^{* *}$ & $40-49$ & 6.593 \\
\hline Age of women & & Age of women & \\
\hline Less than 25(ref) & & Less than 25 (ref) & \\
\hline $25-35$ & $6.536^{*}$ & $25-35$ & 8.902 \\
\hline $35+$ & $4.735^{* *}$ & $35+$ & 6.956 \\
\hline Education level of husband & & Education level of husband & \\
\hline No education(ref) & & No education(ref) & \\
\hline Primary & $.066^{* *}$ & Primary & .840 \\
\hline Secondary & .212 & Secondary & .762 \\
\hline Higher secondary & .613 & Higher secondary & .351 \\
\hline Graduated and above & 1.387 & Graduated and above & .078 \\
\hline Women's education & & women education & \\
\hline No (Ref) & & No (Ref) & \\
\hline Primary & .839 & Primary & $2.519 * * *$ \\
\hline Secondary & 2.0421 & Secondary & $4.707 * * *$ \\
\hline Higher & .605 & Higher & $5.758 * * *$ \\
\hline Women's occupation & & Women's occupation & \\
\hline Not working(Ref) & & not working(Ref) & \\
\hline $\begin{array}{l}\text { Semi-skilled and unskilled } \\
\text { labor }\end{array}$ & $.320^{*}$ & $\begin{array}{l}\text { Semi-skilled and unskilled } \\
\text { labor }\end{array}$ & $.439 * *$ \\
\hline Business and service & 1.931 & Business and service & $2.571^{*}$ \\
\hline Couple's income(Taka) & & Couple's income & \\
\hline Less than 10,000 (Ref) & & Less than 10,000 (Ref) & \\
\hline $10,000-20,000$ & 2.558 & $10,000-20,000$ & 1.391 \\
\hline Above 20,000 & $4.186^{*}$ & Above 20,000 & 1.641 \\
\hline $\begin{array}{l}\text { Current children } \\
0 \text { (Ref) }\end{array}$ & & $\begin{array}{l}\text { Current children } \\
0 \text { (Ref) }\end{array}$ & \\
\hline 1 & 1.546 & 1 & $3.361^{* *}$ \\
\hline 2 & 1.508 & 2 & $8.437 * * *$ \\
\hline $3+$ & 1.546 & $3+$ & $3.361 * *$ \\
\hline \multirow{2}{*}{$\begin{array}{l}\text { Number of methods known } \\
\text { Less than five(ref) }\end{array}$} & & $\begin{array}{l}\text { Number of methods } \\
\text { known }\end{array}$ & \\
\hline & & Less than five(ref) & \\
\hline Above five & 1.301 & Above five & $2.169^{* *}$ \\
\hline Media exposure & & Media exposure & \\
\hline No (Ref) & & No (Ref) & \\
\hline Yes & 1.856 & Yes & .874 \\
\hline
\end{tabular}

Significant at ${ }^{*} p<0 \cdot 10 ;{ }^{* *} p<0 \cdot 05 ;{ }^{* * *} p<0 \cdot 01$; 


\subsection{Effects of Spousal Communication on Contraceptive Method Choice}

Spousal communication was related to use modern contraceptive method. When spousal communication was favorable, couples were 1.904 times more likely to use modern contraceptive than not using any method. Similarly, couples were 2.703 times more likely to use traditional method than not using any method when spousal communication was favorable. So spousal communication is positively related to use modern and traditional method

\subsection{Effects of Other Socio-Demographic Variables on Contraceptive Method Choice}

Women with higher education were more likely to use modern contraceptive than not using any method. Couples who had knowledge on above five methods on contraceptive were 2.169 times more likely to use modern contraceptive method than not using any method. Husband hold age $40-49$ years, were 6.596 times more likely to use modern method and 6.939 times more likely to use traditional method than not using any method and Husband age hold 30-40 years were 2.740 times more likely to use modern method and 4.352 times more likely to use traditional method than not using any method.

women age hold $35+$ years, were 6.956 times more likely to use modern method and 4.735 times more likely to use traditional method than not using any method and women age hold 25-35, were 8.902 times more likely to use modern method and 6.536 times more likely to use traditional method than not using any method. Couples whose had one, two and three and above children, were 3.361, 8.437 and 3.61 times more likely to use modern method than not using any methods. Women who had business and services work were 2.571 times more likely to use modern contraceptive than not using any method.

\section{Discussion and Conclusion}

The results show that spousal communication was associated with contraceptive use and methods choice in Bangladesh. Spousal communication is more important to couples that improve share agreement on contraceptive use and method choice (Berhane et al., 2001). Couples who discuss about family planning are more likely to use contraceptive because there is a mutual understanding and decision-making process on fertility and preference of method choice. As Bangladesh is a male dominate country, women are faced many problems in taking about decision on childbirth and their preference always ignore in order to of choice of method. In Bangladesh inter-spousal communication about family planning has not been established as a cultural practice (Kamal \& Islam, 2012). Almost all of the family planning programs considered women as the main clients, attempted to understand their behavior and attitudes, engaged to educate them about contraceptive knowledge and use, (Tuloro et al., 2006). But the family planning program will not be successes, if their husband not approve. Here, inter-spousal communication can play an important role to inspire their husband about to take small family size and appropriate method choice and better reproductive health services. Contraceptive use and preference of modern contraceptive will increase if women occupation status increases because their economic support give them more control over reproductive health and desire to small family size. Women higher education showed positive effects on the use on contraceptive. Women who have higher education are more likely to use modern contraceptive than who have no education. Educated women had more knowledge and more care full on their reproductive health. In Bangladesh, current living children are an important factor for using contraceptive. Couples have living children are more likely to use contraceptive than how had no children.

So, inter-spousal communication largely influenced to couples to take small family size and suitable and flexible method choice in Bangladesh. Family planning program should be emphasis on husband wife communication about their reproductive issues. Male should be included in family planning program. Male should be inspired to their wives to include about their fertility related issues and family planning program.

\section{References}

Berhane, A., Biadgilign, S., Amberbir, S., Morankar, S., Berhane, A., \& Deribe, K. (2011). Men's knowledge and spousal communication about modern family planning methods in Ethiopia. African Journal of Reproductive Health, 15(4), 24-32.

DeRosem, L. F., Dodoo, N. F., Ezen, A. C., \& Owuor, T. O. (2004). Does Discussion of Family Planning Improve of Partner's Attitude Toward Contraceptives? International Family Planning Perspectives (2004), 30(2), 87-93. http://dx.doi.org/10.1363/3008704

Islam, M. A., Padmadas, S. S., \& Smith, P. W. F. (2010). Understanding family planning communication Bangladesh. DHS. GENUS, LXVI(1), 1-15. Retrieved from http://scistat.cilea.it/index.php/genus/article//download/76/112 
Kamal, S. M., \& Islam, M. A. (2002). Inter-spousal communication on family planning and its effects on contraceptive adaptation in Bangladesh. Asia Pac J Public Health, 2012(24), 506-521.

Karvande, S. S. (2009). Process of couple communication in reproductive health among rural married couples in India. PhD thesis. University of Basel. Retrieved from http://edoc.unibas.ch//1064/1/PhD_Shilpa_Santosh _Karvande_2009.pdf

Nahar, N. (2005). Effect of spousal communication on use of contraceptives among rural women of Bangladesh. Retrieved from http://iussp2005.princeton.edu/papers/51811

Ogunjuyigbe, P. O., Ojofeitimi, E. O., \& Liasu, A. (2009). Spousal communication, changes in partner attitude, and contraceptive use among the Yorubas of Southwest Nigeria. Indian J Community Med, 34(2), 112-116. http://dx.doi.org/10.4103/0970-0218.51232

Rasheed, N., Khan, Z., Khalique, N., \& Hakim, S. A. R. (2010). Inter-spouse communication and acceptance of family planning. Indian Journal of Community Health, 23(2), 72-74.

Shrestha, D. P. (2009). Husband-wife communication and family planning decision-making in Nepal. Retrieved from http://paa2009.princeton.edu/papers/91982

Tuloro, T. W., Deressa, A. A., \& Davey, G. (2006). The role of men in contraceptive use and fertility preference in Hossana Town, Southern Ethiopia. Ethiopian Journal of Health Development, 20(3), 152-159. Retrieved from http://www.ajol.info/index.php/ejhd/article/download/46826/33220

\section{Copyrights}

Copyright for this article is retained by the author(s), with first publication rights granted to the journal.

This is an open-access article distributed under the terms and conditions of the Creative Commons Attribution license (http://creativecommons.org/licenses/by/3.0/). 